University of Warwick institutional repository: http://go.warwick.ac.uk/wrap This paper is made available online in accordance with publisher policies. Please scroll down to view the document itself. Please refer to the repository record for this item and our policy information available from the repository home page for further information.

To see the final version of this paper please visit the publisher's website. Access to the published version may require a subscription.

Author(s): B. M. M. McGregor, R. J. P. Lander, P. J. Phillips, E. H. C. Parker, and T. E. Whall Article Title: Temperature-dependent Hall scattering factor and drift mobility in remotely doped Si:B/SiGe/Si heterostructures

Year of publication: 1999

Link to published version: http://dx.doi.org/10.1063/1.123513

Publisher statement: None 


\title{
Temperature-dependent Hall scattering factor and drift mobility in remotely doped $\mathrm{Si}: \mathrm{B} / \mathrm{SiGe} / \mathrm{Si}$ heterostructures
}

\author{
B. M. M. McGregor, ${ }^{a)}$ R. J. P. Lander, P. J. Phillips, E. H. C. Parker, and T. E. Whall \\ Department of Physics, University of Warwick, Coventry, CV4 7AL, United Kingdom
}

(Received 23 November 1998; accepted for publication 5 January 1999)

\begin{abstract}
Hall-and-Strip measurements on modulation-doped SiGe heterostructures and combined Hall and capacitance-voltage measurements on metal-oxide-semiconductor (MOS)-gated enhancement mode structures have been used to deduce Hall scattering factors, $r_{H}$, in the $\mathrm{Si}_{1-x} \mathrm{Ge}_{x}$ two-dimensional hole gas. At $300 \mathrm{~K}, r_{H}$ was found to be equal to 0.4 for $x=0.2$ and $x=0.3$. Knowing $r_{H}$, it is possible to calculate the $300 \mathrm{~K}$ drift mobilities in the modulation-doped structures which are found to be $400 \mathrm{~cm}^{2} \mathrm{~V}^{-1} \mathrm{~s}^{-1}$ at a carrier density of $3.3 \times 10^{11} \mathrm{~cm}^{-2}$ for $x=0.2$ and 300 $\mathrm{cm}^{2} \mathrm{~V}^{-1} \mathrm{~s}^{-1}$ at $6.3 \times 10^{11} \mathrm{~cm}^{-2}$ for $x=0.3$, factors of between 1.5 and 2.0 greater than a Si $p$ MOS control. (C) 1999 American Institute of Physics. [S0003-6951(99)03509-3]
\end{abstract}

The widespread interest in SiGe heterostructures for field effect transistors, and particularly complementary metal-oxide-semiconductor (CMOS) applications, stems from their huge potential due to the enhanced carrier mobilities in these materials. To refine epitaxial growth conditions, the rapid measurement of room temperature carrier mobility is needed from modulation doped samples, which suffer from the influence of parallel conduction paths. Although the room temperature hole mobilities reported to date in $\mathrm{SiGe}$ are especially exciting, ${ }^{1}$ reliable data are still in short supply.

In this work we report the application of the Hall-andStrip (HS) technique to the solution of this problem. The method has recently been used by Garchery et al. ${ }^{2}$ to obtain a room temperature electron gas mobility of $2150 \mathrm{~cm}^{2} / \mathrm{V} \mathrm{s}$ $\left(n_{s}=1.1 \times 10^{12} \mathrm{~cm}^{-2}\right)$ in modulation doped strained silicon. However, its application to the hole gas poses specific problems because of the lower carrier mobilities for $x<0.4$ in $\mathrm{Si}_{1-x} \mathrm{Ge}_{x}$, and the different natures of the parallel conduction carriers for electrons and holes at room temperature.

A further complication, in the case of holes as compared to electrons, is the nonparabolicity of the energy dispersion curve and the anisotropic nature of the constant energy surface. This means that the carrier drift mobility differs from the Hall mobility by the Hall scattering factor, $r_{H}$, which can be less than unity depending on the details of the band structure and on the carrier scattering mechanism. ${ }^{3}$ The addition of germanium causes a further "warping" of the valence band constant energy surface which produces another modification of the Hall mobility. ${ }^{4}$ The corollary is that $r_{H}$ is likely to be different for unstrained bulk SiGe, strained bulk $\mathrm{SiGe}$, and the two-dimensional hole gas (2DHG) in strained SiGe. Incorrect assumptions about the value of $r_{H}$ can lead to erroneous conclusions about the relative importance of processes such as alloy scattering.

Measurements of $r_{H}$ in bulk strained and unstrained $p$-SiGe have been made previously by comparing a $\mathrm{SiGe}$ doping concentration, determined by secondary ion mass spectroscopy (SIMS), to the electrical Hall carrier

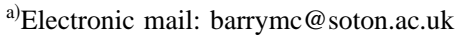

concentration. ${ }^{4,5}$ Discrepancies between the reports using this method are likely to be due to the unknown acceptor activation level and SIMS sputter rate dependence on the germanium content. In the present letter we report measurements on the temperature dependence of $r_{H}$ in the 2DHG. The results have been obtained from HS measurements on modulation doped structures, and from a comparison of the apparent and true carrier concentrations determined by Hall and capacitance-voltage $(C-V)$ measurements, respectively, in MOS gated enhancement mode structures.

The details of the HS process are described elsewhere. ${ }^{6}$ Suffice to say that the silicon surface is over-etched until the depletion of the dopant layer by the surface states causes a reduction in the $2 \mathrm{DHG}$ carrier concentration. Detailed modeling shows that, to a good approximation, all free carriers are then confined to the quantum well at room temperature for direct measurement. ${ }^{6}$ If we assume that the Hall scattering factor is unity at low temperature, as indicated by the similarity of the sheet carrier concentration determined by $\mathrm{SdH}$ and Hall measurements, ${ }^{7}$ and that the $2 \mathrm{DHG}$ carrier concentration is invariant with temperature, ${ }^{6}$ then the ratio of the high and low temperature measured Hall factor, $R_{H}$, provides the Hall scattering factor:

$$
r_{H}=R_{H}(T) / R_{H}^{9 \mathrm{~K}} \text {. }
$$

All structures were grown by solid source molecular beam epitaxy (SSMBE) in a VG Semicon V90S system. The (001)-oriented $n^{-}$substrates for the modulation doped structures were RCA cleaned then dipped in a $\mathrm{HF}(5 \%)$ solution for $20 \mathrm{~s}$ prior to loading in the vacuum system. ${ }^{8}$ An in situ $890^{\circ} \mathrm{C}$ flux clean was used prior to growth to remove any remaining surface oxide.

Two heterostructures were grown for HS analysis; 300 $\mathrm{nm}$ of undoped silicon was first grown to provide a good surface for a $15 \mathrm{~nm} \mathrm{Si} i_{0.8} \mathrm{Ge}_{0.2}\left(\mathrm{Si}_{0.7} \mathrm{Ge}_{0.3}\right)$ alloy layer. A $7 \mathrm{~nm}$ $(5 \mathrm{~nm})$ undoped silicon setback was then grown, followed by a $50 \mathrm{~nm}(28 \mathrm{~nm})$ boron supply layer doped at 2 $\times 10^{18} \mathrm{~cm}^{-3}$. The alloy and subsequent layers were grown at $700{ }^{\circ} \mathrm{C}\left(510^{\circ} \mathrm{C}\right)$.

After growth, the HS wafers were cleaved into several specimens measuring $\sim 1 \mathrm{~cm}^{2}$. Each sample was then etched 


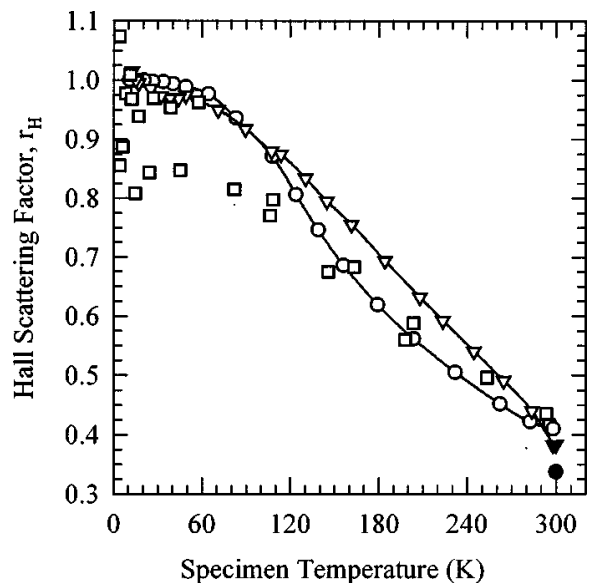

FIG. 1. Hole Hall scattering factor determined for $\mathrm{Si}_{0.8} \mathrm{Ge}_{0.2}$ (circles by $\mathrm{HS}$, squares by $C-V$ ) and $\mathrm{Si}_{0.7} \mathrm{Ge}_{0.3}$ (triangles by $\mathrm{HS}$ ). Filled symbols are for bulk strained SiGe taken from Ref. 4.

for different times at a rate of $2-3 \mathrm{~nm} / \mathrm{min}$ in $8 \mathrm{HNO}_{3}(70 \%): 4 \mathrm{H}_{2} \mathrm{O}: 1 \mathrm{HF}(0.5 \%)^{2}$, rinsed, and then dried. Standard van der Pauw (vdP) Greek mesa crosses were fabricated on every specimen using a simple photolithographic etch process. Finally, ohmic contacts were made to the $2 \mathrm{DHG}$ by patterned, sputtered, $\mathrm{Al}(\geqslant 1 \mathrm{wt} . \% \mathrm{Si})$ pads which were furnace annealed.

The Hall carrier concentration and mobility were determined at temperatures between 9 and $300 \mathrm{~K}$ for each of the etched specimens, using an accurate alternating-current (ac) $(13 \mathrm{~Hz})$ van der Pauw and Hall measurement system with a maximum measurement current of $0.5 \mu \mathrm{A}$, and a magnetic field of $0.41 \mathrm{~T}$.

The growth and fabrication details of the MOS gated $\mathrm{Si}_{0.8} \mathrm{Ge}_{0.2}$ heterostructures are described elsewhere. ${ }^{9}$ Measurement of the Hall coefficient for a carrier concentration of $3.3 \times 10^{11} \mathrm{~cm}^{-2}$, as determined by MOS $C-V$ measurements, enabled us to determine the Hall scattering coefficient in these enhancement mode devices. While the determination of the Hall scattering factor using the MOS gated structures was simpler to implement, the specimen processing cost and large lead time made this method unattractive.

During application of the HS procedure on the $\mathrm{Si}_{0.8} \mathrm{Ge}_{0.2}$ $\left(\mathrm{Si}_{0.7} \mathrm{Ge}_{0.3}\right)$ heterostructure, the $9 \mathrm{~K}$ sheet carrier concentration fell from $6 \times 10^{11}\left(10^{12} \mathrm{~cm}^{-2}\right)$ to $3.3 \times 10^{11} \mathrm{~cm}^{-2}(6.3$ $\left.\times 10^{11} \mathrm{~cm}^{-2}\right)$ after a $9 \mathrm{~min}(4.5 \mathrm{~min})$ etch, indicating over etching. The corresponding $9 \mathrm{~K}$ 2DHG Hall mobility was $1800 \mathrm{~cm}^{2} / \mathrm{V} \mathrm{s}\left(800 \mathrm{~cm}^{2} / \mathrm{V} \mathrm{s}\right)$. Despite the relatively low mobility of the nonoptimal $\mathrm{Si}_{0.7} \mathrm{Ge}_{0.3}$ heterostructure, ${ }^{10}$ it is respectable when compared to other published reports. ${ }^{11}$ The hole Hall mobility in the gated $\mathrm{Si}_{0.8} \mathrm{Ge}_{0.2}$ heterostructure was $2700 \mathrm{~cm}^{2} / \mathrm{V} \mathrm{s}$ at $4.2 \mathrm{~K}$. The mobilities of these samples are not particularly high when compared to some of the best, for example $6000 \mathrm{~cm}^{2} \mathrm{~V}^{-1} \mathrm{~s}^{-1}$ for $x=0.2$ at $4 \mathrm{~K}^{1}$, and is attributed to the use of nonoptimal growth conditions. However, the material was judged to be of an adequate quality for this investigation.

The calculated 2DHG Hall scattering factors are shown in Fig. 1. The good agreement between the $C-V$ and HS methods of determining $r_{H}$ in $\mathrm{Si}_{0.8} \mathrm{Ge}_{0.2}$ confirm that the HS method was suitable for this application.

In all cases, the fall in the Hall scattering factor with Downloaded 06 Jul 2009 to 137.205 .202 .8. Redistribution subject

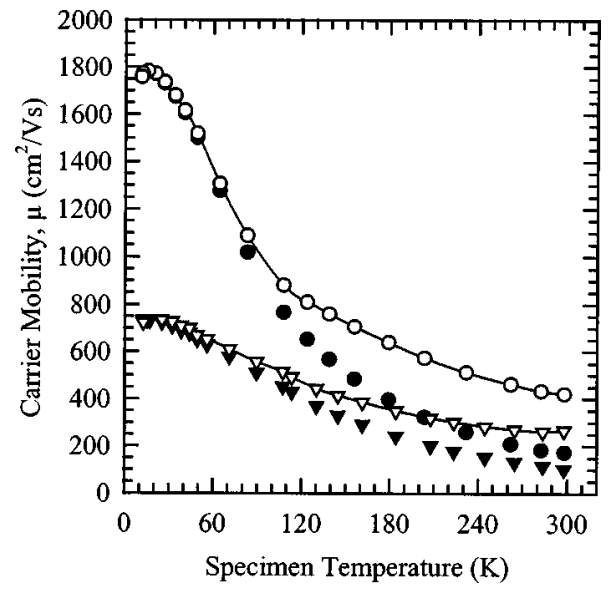

FIG. 2. 2DHG mobility in $\mathrm{Si}_{0.8} \mathrm{Ge}_{0.2}$ (circles) and $\mathrm{Si}_{0.7} \mathrm{Ge}_{0.3}$ (triangles). Filled symbols are for Hall mobility, open circles are for calculated drift mobility.

rising temperature is consistent with an increased constant energy surface anisotropy (the carrier energy changes from $\sim 1 \mathrm{meV}$ at $9 \mathrm{~K}$ to $\sim 26 \mathrm{meV}$ at $300 \mathrm{~K}$ ). According to the theoretical predictions of Fu et al. ${ }^{4}$ the $300 \mathrm{~K}$ hole Hall scattering factor should be 0.2 in both strained bulk $\mathrm{Si}_{0.8} \mathrm{Ge}_{0.2}$ and $\mathrm{Si}_{0.7} \mathrm{Ge}_{0.3}$ with a carrier concentration of 5 $\times 10^{17}-10^{18} \mathrm{~cm}^{-3}$, which is lower than the value of 0.4 measured in this work. The discrepancy can be understood in terms of the elementary methods of Allgaier ${ }^{12}$ (who considered the shapes of simple energy surfaces) and the different dimensionalities of the carriers in the two cases.

Figure 2 shows the measured $\mathrm{Si}_{0.8} \mathrm{Ge}_{0.2}$ and $\mathrm{Si}_{0.7} \mathrm{Ge}_{0.3}$ hole Hall mobility and the calculated drift mobility. In both cases, the $300 \mathrm{~K}$ drift mobility is significantly higher than the corresponding Hall mobility since the Hall scattering factor is less than unity. The discrepancy between $300 \mathrm{~K}$ mobilities as deduced from mobility spectrum investigations and Hall measurements, observed by Höck and co-workers, ${ }^{13}$ can now be understood in terms of Hall scattering factors lying in the range of $0.2-0.3$ for $\mathrm{Si}_{1-x} \mathrm{Ge}_{x}$ compositions $0.7 \leqslant x \leqslant 1$. The room temperature drift mobility for both of these heterostructures is significantly greater than that measured in the $\mathrm{Si}$ $p$ MOS control in our laboratory, which varies from 200 $\mathrm{cm}^{2} \mathrm{~V}^{-1} \mathrm{~s}^{-1}$ at $1 \times 10^{11} \mathrm{~cm}^{-2}$ to $180 \mathrm{~cm}^{2} \mathrm{~V}^{-1} \mathrm{~s}^{-1}$ at 1 $\times 10^{12} \mathrm{~cm}^{-2}$ for a background donor concentration of $<10^{15} \mathrm{~cm}^{-2}$.

The present work, in which we have carried out the first measurements of Hall scattering factors in the SiGe 2DHG is significant and of interest for a number of reasons. It demonstrates that Hall measurements are not sufficient for assessing SiGe device potential but must be accompanied by knowledge of $r_{H}$. It indicates a possible strongly anisotropic conduction which needs further investigation and, finally, it should act as a stimulus for theoretical calculations of the band structure of the SiGe 2DHG, which are in short supply.

In conclusion, the Hall-and-Strip technique has been successfully applied to remotely doped $p$-type heterostructures to determine the 2DHG Hall scattering factor and drift mobility as a function of temperature. The applicability of this cheap and convenient technique is confirmed by effective mobility measurements on an MOS gated enhancement mode structure. ${ }^{9}$ Despite the nonoptimal growth conditions o AlP license or copyright; see http://apl.aip.org/apl/copyright.jsp 
used, the hole drift mobility is significantly higher than in $\mathrm{Si}$ $p$ MOS and offers good prospects of enhanced MOS device performance.

The authors would like to thank G. Höck for sight of his letter prior to publication. B. M. McGregor and R. J. P. Lander would like to thank the EPSRC who supported this work.

${ }^{1}$ T. E. Whall and E. H. C. Parker, J. Phys. D 31, 1397 (1998).

${ }^{2}$ L. Garchery, I. Sagnes, P. Warren, J.-C. Dupuy, and P. A. Badoz, J. Cryst. Growth 157, 367 (1995).

${ }^{3}$ J. F. Lin, S. S. Li, L. C. Linares, and K. W. Teng, Solid State Electron. 24, 827 (1981).

${ }^{4}$ Y. Fu, K. B. Joelsson, K. J. Grahn, W.-X. Ni, G. V. Hansson, and M. Willander, Phys. Rev. B 54, 11317 (1996).

${ }^{5}$ T. Manku, J. M. McGregor, A. Nathan, D. J. Roulston, J.-P. Noel, and D. C. Houghton, IEEE Trans. Electron Devices 40, 1990 (1993).
${ }^{6}$ B. M. McGregor, R. J. P. Lander, P. J. Phillips, C. P. Parry, S. Roy, E. H. C. Parker, and T. E. Whall (unpublished).

${ }^{7}$ T. W. Kim, T. W. Kang, and K. L. Wang, Solid State Commun. 99, 47 (1996).

${ }^{8}$ P. J. Grunthaner, F. J. Grunthaner, R. W. Fathauer, T. L. Lin, M. H. Hecht, L. D. Bell, W. J. Kaiser, F. D. Schowengerdt, and J. H. Mazur, Thin Solid Films 183, 197 (1989).

${ }^{9}$ R. J. P. Lander, C. J. Emeleus, B. M. McGregor, E. H. C. Parker, T. E. Whall, A. G. R. Evans, and G. P. Kennedy, J. Appl. Phys. 82, 5210 (1997).

${ }^{10}$ T. J. Grasby, R. Hammond, C. P. Parry, P. J. Phillips, B. M. McGregor, R. Morris, G. Braithwaite, E. H. C. Parker, and T. E. Whall (unpublished).

${ }^{11}$ R. A. Kiehl, P. E. Batson, J. O. Chu, D. C. Edelstein, F. F. Fang, B. Laikhtman, D. R. Lombardi, W. T. Masselink, B. S. Meyerson, J. J. Nocera, A. H. Parsons, C. L. Stanis, and J. C. Tsang, Phys. Rev. B 48, 11946 (1993).

${ }^{12}$ R. S. Allgaier, Phys. Rev. 158, 699 (1967).

${ }^{13}$ G. Höck, M. Gluck, T. Hackbarth, H. J. Herzog, and E. Kohn, Thin Solid Films (to be published). 